NoIA, Camiño (ed.): Imaxes de muller: representación da feminidade en mitos, contos e lendas. Vigo: Universidade de Vigo, 2012, 330 p.

\title{
Imaxes de muller
}

Emili SAMPER PRUNERA

Universitat Rovira i Virgili, Tarragona

Des de l'any 2003, el grup internacional ERGON / GRENO (European Research Group on Oral Narrative / Grup de Recerca Europeu en Narrativa Oral), format per especialistes en l'estudi de la narrativa oral d'universitats i centres de recerca d'arreu d'Europa, es reuneix de manera periòdica per debatre i estudiar diferents qüestions al voltant de la literatura oral i, especialment, de la rondallística. Tot i que, formalment, el grup es va constituir durant el quart congrés internacional de catalogadors (The Romantic Folktales-Novellae. Boundaries and Classification), celebrat a Atenes del 8 al Io de maig de 2008, el seu origen es remunta al mes de novembre de 2003, a Tolosa, amb la jornada que va significar el tret de sortida d'aquestes trobades, titulada «Nommer/classer les contes populaires». La resta de trobades s'han celebrat des d'aleshores en diferents seus i s'han dedicat a diferents aspectes de la narrativa oral. Així, la ciutat occitana de Pau va acollir la segona trobada dedicada a la «Tradition orale et récits facétieux», celebrada del 3 al 4 de març de 2006. Palma va ser la seu de la següent trobada, celebrada a finals de novembre d'aquest mateix any, i dedicada a «La classificació de les rondalles: tipus, gèneres, arxius». Després del congrés ja esmentat celebrat a Atenes, Lisboa i Torre das Vargens van acollir del 8 a l'ir de juny de 20 oro la trobada dedicada als relats que es troben «Entre conte et légende». Santiago de Compostela va ser la seu de la sisena trobada, celebrada a finals de 20 I i dedicada a l'estudi de «Les personnages féminins dans les légendes». Finalment, Tarragona va acollir, els dies 25 i 26 d'octubre de 20I2, de la mà de l'Arxiu de Folklore del Departament de Filologia Catalana de la Universitat Rovira i Virgili, la darrera trobada celebrada fins ara, dedicada a l'estudi de les formes breus de la narrativa oral.

Un dels punts forts d'aquestes trobades és el debat que es fomenta entre els diferents participants. D'aquesta manera, les intervencions de cada investigador es veuen enriquides amb la relació directa amb la resta de col-legues del grup, que poden aportar matisos, observacions i reflexions al voltant del tema tractat. Aquest enriquiment es pot reflectir en les versions escrites de les diferents comunicacions publicades a posteriori. És el cas del volum que ara ens ocupa, Imaxes de muller, que recull bona part de les intervencions de la (gairebé) vintena d'especialistes en folklore i literatura oral de diversos països (Alemanya, Grècia, França, Portugal, Espanya, Dinamarca) que van participar en la sisena trobada. Organitzada per la Universitat de Vigo (amb Camiño Noia al capdavant) i la Fundación Carlos Casares, aquesta trobada es va celebrar entre els dies 7 i II de novembre de 20 II a l'Hotel Balneari Mondariz. És també de la mà d'aquestes dues institucions, amb Camiño Noia com a responsable, que s'ha realitzat l'edició del llibre. Les comunicacions i els debats de la trobada es van centrar en el tema de la figura femenina en el llegendari europeu, analitzada des de punts de vista molt diversos i a la llum que aporten nombrosos relats llegendaris que giren entorn de la figura femenina en relació amb el seu context social. El subtítol del volum (Representación da femi- 
nidade en mitos, contos e lendas) recull, com és evident, aquest mateix esperit, amb l'objectiu de reflexionar sobre les diferents representacions femenines presents en la narrativa oral tenint en compte les diferents àrees culturals dels membres que integren GRENO i que participen en el llibre. Es tracta, parafrasejant Noia al pròleg, d'un tema essencial per comprendre millor, en aquesta etapa tecnològica en què vivim, els conflictes humans, personals i col-lectius (p. I6).

Les més de tres-centes pàgines que formen Imaxes de muller es divideixen en quatre seccions diferents, segons el subgènere narratiu en què s'inclou l'estudi de la figura femenina: I) mites i llegendes de la feminitat; 2) la representació de la dona entre la rondalla i la llegenda; 3 ) imatges de dona en les llegendes medievals portugueses, i 4) dues llegendes urbanes de Buenos Aires. El gruix dels estudis el trobem en els dos primers apartats, amb vuit i set articles, respectivament, ja que els dos darrers apartats estan formats per un article cadascun.

La primera secció s'enceta amb l'estudi d'Emmanouela Katrinaki titulat «Les femmes, les fées et leurs enfants. Aspects de la maternité dans les légendes et les croyances grecques». Katrinaki contextualitza les llegendes gregues en relació amb el marc europeu i ho fa tenint en compte treballs ja clàssics com el de les anomenades llegendes migratòries de Christiansen. ${ }^{\mathrm{I}}$ El corpus llegendístic grec analitzat se centra especialment en l'estudi de les fades i es divideix en tres tipus de narracions: les que protagonitzen fades que segresten infants i després els retornen, les històries de fades que es casen amb homes mortals i tenen descendència amb ells i, finalment, l'intercanvi d'infants propiciats per la lletjor i la malaltia dels descendents de les fades. L'autora veu en aquest tipus de relats una coincidència entre els papers de les fades i les mares mortals, que coincideix, alhora, amb el dels fills intercanviats. Es tracta, en el fons, de l'expressió del mateix sentiment de protecció de les mares vers les seves criatures, sentiment que pot derivar en la negació de la malaltia de la criatura.

Del corpus llegendístic grec passem al danès, amb l'article de Michèle Simonsen sobre «La maternité dans le légendaire danois». A partir de l'extens treball de recol-lecció d'Evald Tang Kristensen de finals del segle XIx, format per set volums, ${ }^{2}$ Simonsen s'endinsa en l'estudi de les llegendes daneses al voltant de la maternitat que divideix en dos grans grups: les anomenades «revenantes» i els homes llop. En el primer cas, ens trobem amb una tipologia formada per tres classes d'éssers diferents que tornen del més enllà: les bruixes, les mares infanticides i les dones embarassades que moren abans de donar a llum. En el segon cas, es tracta d'un grup específic de llegendes daneses que reflecteixen, en el fons, les dificultats de la maternitat en les societats rurals del segle XIX. Simonsen analitza els rituals que precedeixen el naixement dels fills sense dolor i que desemboquen en l'origen d'aquests éssers. Alhora, ofereix també el vessant contrari, format pels rituals que porten els homes llop a lliurar-se de la seva maledicció.

Camiño Noia i Gonzalo Navaza signen conjuntament l'article «Lendas en pedra da maternidade», on estudien, a partir dels precedents europeus, la impor-

I. Christiansen, Reidar T. (1958): The migratory legends. A proposed list of types with a systematic catalogue of the Norwegian variants. Folklore Fellows' Communications I75. Hèlsinki: Suomalainen Tiedeakatemia.

2. KRISTENSEN, Edwald Tang (I892-I9OI): Danske Sagn som de har lydt i folkemund. Udelukkende efter utrykte kilder. Copenhaguen: Århus / Silkeborg, 7 vols. [Copenhaguen: Arnold Busk, I980, 8 vols.] 
tància del culte a les pedres amb poders sobrenaturals i dels mites que se'n deriven en terres gallegues. Els autors se centren, principalment, en dues mostres concretes que representen figures femenines i que es troben situades a Outeiro do Filladuiro i a Outeiro de Coirós («A Moura de Pena Furada»). A més de relacionar aquestes restes amb les històries d'éssers femenins amb poders sobrenaturals als quals s'atribueix la seva presència, els autors analitzen l'etimologia de la paraula «moura / mouro», es fan ressò de la sacralització dels santuaris pagans i relacionen aquestes restes amb altres pedres de la fertilitat que es troben en altres indrets propers, com Portugal o França. Pel que fa a l'estudi rondallístic, els autors donen noves pistes d'interpretació de dues versions d'una rondalla «estranya», titulada «A muller que arrefriaba o marido», classificada inicialment al catàleg tipològic gallec de Noia amb el subtipus 9IO* $\mathrm{E}^{3}$ i que ara relacionen amb el culte a les pedres de fertilitat estudiades (p. 54).

El personatge llegendari de Melusina, proper a les fades i representat iconogràficament amb forma de serp en la part inferior del seu cos, centra l'atenció dels dos articles següents. José Ramón Mariño Ferro, a «Mouras y Melusinas», analitza les versions gallegues d'aquestes llegendes que presenten la transformació de les donzelles en serps i busca els punts en comú amb les rondalles d'encantament amb el paper de la serp com a jove encantada i guardià del tresor. L'autor estudia la relació entre les donzelles amb forma de serp de les llegendes gallegues i les melusines i fa notar el context concret en què apareixen. El poder de seducció d'aquest personatge (simbolitzat pel cabell i per la pinta) fan de la dona un ésser perillós i malèfic, com evidencia el context religiós que presenta una triple relació entre la serp (que manifesta el poder del verí), la dona (que representa la maldat del gènere femení) i el dimoni.

Per la seva banda, Isabel Cardigos es pregunta a «"Dona Marinha”: Uma figura melusínica?» per la relació entre Melusina i la llegenda «Dona Marinha», inclosa al Livro de Linhagens do Conde Dom Pedro de José Mattoso. ${ }^{4}$ L'autora compara aquesta llegenda amb la versió siciliana de Melusina i amb altres versions que tenen punts en comú amb aquesta història. Ambdós treballs (el de Mariño Ferro i el de Cardigos) tenen en compte la versió medieval de la llegenda, escrita a finals del segle xiv per Jean d'Arras. ${ }^{5}$

El següent article d'aquesta primera secció és l'estudi de Jesús Suárez López al voltant de «La mujer salvaje que voltea sus pechos sobre los hombros: una leyenda asturiana y sus paralelos universales». L'autor pren com a punt de partida el treball de camp realitzat per ell mateix a Astúries entre els anys I998 i I999 en el qual va recollir, entre d'altres, catorze versions d'una llegenda sobre l'expulsió dels moros en l'anomenada batalla de «La Matancia», on l'única supervivent és una noia que ofereix un tresor a canvi de la seva vida. En tres d'aquestes versions la noia està dotada amb uns pits tan grans que, quan corre, se'ls posa sobre l'espatlla. Aquesta llegenda asturiana té similituds amb altres versions europees orals i literàries i està inclosa dins el catàleg de motius de Thompson i en dos tipus

3. NoIA, Camiño (20IO): Catálogo tipolóxico do conto galego de tradición oral. Vigo: Servizo de Publicacións da Universidade de Vigo.

4. Mattoso, José (1980): Livro de Linhagens do Conde D. Pedro. Lisboa: Academia das Ciências.

5. Coneguda com Melusina o La Noble Historia de Lusignan i editada i traduïda en espanyol per Carlos Alvar a Siruela dins la Biblioteca Medieval (I983). 
de l'índex d'Aarne-Thompson-Uther (p. 85-87). ${ }^{6}$ Suárez observa com aquest arquetip femení apareix com a reflex d'un passat mitològic indoeuropeu i, alhora, dins d'un present exòtic que es pot relacionar amb diferents espècies descrites als llibres de viatges (p. 89-90). ${ }^{7}$

Antonio Reigosa estudia un vessant diferent de la feminitat a «A filla que aleita ao pai ou a Caridade Romana. Fortuna deste conto na tradición oral e iconogràfica de Galicia». Concretament, se centra en el vell mite sobre l'alletament i les diferents interpretacions que ha rebut segons el context moral o religiós de l'època. L'autor explica les propietats de la llet de la dona i els seus usos i es fa ressò de la presència d'aquesta història en la literatura llatina (amb Plini) i en la literatura del Renaixement, així com en altres arts. La seva popularitat fa que aparegui en pintures, escultures i també en el cinema (amb exemples com El crimen de Cuenca, I979, i La charité Romaine, 2008) (p. I07). Reigosa se centra de manera particular en les versions gallegues i també assenyala la presència d'aquest motiu a diferents catàlegs tipològics (p. IO9-IIO), com ara el d'Uther (ATU 927, subtipus B, i 985*), Boggs $\left(927^{*} \mathrm{~A}\right)$ o Camarena-Chevalier $(927, \mathrm{~b}){ }^{8}$

L'estudi que tanca aquest primer bloc és el de Hans-Jörg Uther, titulat «Europäische Ätiologien über die Namen von Gesteninsformationen am Beispiel der Sagen von der Lorelei und vom Jungfernsprung». L'autor centra l'atenció en les versions alemanyes de les llegendes de caràcter etiològic al voltant del tema recurrent de la innocent perseguida i les relaciona amb altres variants presents en textos antics, així com en el context cristià i, fins i tot, turístic.

La segona secció del llibre està formada per set articles que tenen en compte la representació de la dona i les dificultats d'adscripció de determinats relats que es troben a mig camí entre la rondalla i la llegenda. Aquest és un tema de gran interès tant per la temàtica tractada com per posar de manifest els trets que dificulten l'adscripció d'aquest tipus de relats a aquests dos gèneres folklòrics. Anna Angelopoulos enceta la secció amb l'estudi sobre «La figure de la Gorgone dans les légendes et dans les contes merveilleux grecs». La coneguda Gorgona, figura femenina mitològica grega caracteritzada per les serps al cap i la mirada que petrifica, és el tema triat per l'autora que pren com a corpus les llegendes gregues recollides per Nikoalos Politis. ${ }^{9}$ Un dels aspectes més interessants d'aquest estudi és la relació d'aquest ésser mitològic amb Alexandre el Gran, que l'utilitza com a arma, així com l'aparició d'aquesta llegenda com a motiu introductori dels tipus ATU 3I6 i 400.

\footnotetext{
6. Concretament, als motius F232.2, F44I.2.I.2, F460.I.2, Gi23 i F53I.I.5.I (THOMPSON, Stith [1955-58]: Motif-index of folk-literature. Bloomington: Indiana University Press) i a les versions àrabs d'ATU 3 IO i 707 (UTHER, Hans-Jörg [ATU] [2004]: The types of international folktales. A classification and bibliography based on the system of Antti Aarne and Stith Thompson. 3 vols. Folklore Fellows' Communications 284-285-286. Hèlsinki: Suomalainen Tiedeakatemia).

7. Com ara les restes arqueològiques de l'Homo floresiensis, conegut com a Hobbit per la mida reduïda que té.

8. BoggS, Ralph S. (I930): Index of Spanish folktales. Folklore Fellows' Communications 9o. Hèlsinki: Suomalainen Tiedeakatemia; Camarena, Julio; Maxime Chevalier (2003): Catálogo tipológico del cuento folklórico español. Cuentos-novela. Madrid: Centro de Estudios Cervantinos.

9. Politis, Nikolaos [1904] (I998): Paradoseis. Atenes.
} 
La funció simbòlica i social de les llegendes de dones que es transformen en animals centra l'atenció de Paulo Correia. A «Las mujeres y la metamorfosis animal en las leyendas portuguesas de brujas» l'autor analitza el corpus existent a l'Arxiu Portuguès de Llegendes sobre aquest tema i en dóna els trets distintius. Correia parteix també d'un tipus proposat per Christiansen al seu catàleg de llegendes migratòries (concretament, el tipus 3055 «La bruixa ferida») i ressegueix els trets comuns de les set versions de l'arxiu portuguès que hi coincideixen temàticament, així com de les divuit versions que comparteixen el motiu G.2II de Thompson. Aquesta llegenda de bruixes, àmpliament estesa i que també es troba en altres corpus europeus (com el català i l'espanyol, si ens cenyim a l'àmbit peninsular), presenta particularitats en el cas portuguès. Així, Correia fa notar com, en la tradició portuguesa, la bruixa pren la forma d'animal de corral (com ara la gallina o l'ànec), al contrari d'altres tradicions del nord d'Europa, on els animals són la llebre o, més comunament, el gat (p. I44-I45).

La por de l'home davant els comportaments sexualment alliberats de la dona, estudiada a partir del costum anomenat «contar las viejas», és el tema triat per Carlos González Sanz a "Contar las viejas". Apuntes acerca de la libertad sexual de la mujer a través de algunas costumbres y relatos folklóricos del área pirenaica y el norte de la Península Ibérica». L'autor relaciona aquest costum denigrant i humiliant per a l'home amb altres de semblants, així com amb rondalles que tracten el mateix tema o que s'hi poden relacionar. És el cas, per exemple, de relats de bruixes (com el tipus [746C]), ${ }^{\text {IO }}$ de relats de moros, del motiu de la «vagina dentata» o, novament, del personatge de Melusina. Carlos González crida l'atenció sobre una qüestió especialment interessant en relació amb el tema plantejat, com és la del gènere del narrador o narradora del relat folklòric i com la seva visió s'ha de veure reflectida tant en la perspectiva des de la qual explica els fets com també en els mateixos temes triats (p. I75-I78).

La relació entre la llegenda i la rondalla és el tema estudiat per Rafael Beltran a «La niña que le vio los dientes al lobo: cuentos y leyendas entre "Caperucita Roja” (ATU 333) y “La asadura del muerto" (ATU 366)». L'estudi d'aquests dos tipus rondallístics, propers a la llegenda pel seu caràcter extraordinari, n'evidencia el caràcter didàctic. L'autor examina les versions europees i peninsulars d'aquests tipus, amb atenció especial a les del corpus valencià (amb Enric Valor), i mostra les relacions existents entre ambdós a partir dels elements que comparteixen.

«La guerra de sexos en la narrativa oral» és el títol de l'estudi de Josep A. Grimalt, que se centra en la violència (física o no) entre els membres dels dos sexes. L'autor aplica tres categories diferents: els casos de violència de l'home sobre la dona, els de violència de la dona sobre l'home i, finalment, els que són recíprocs. Com a exemples, utilitza versions del tipus ATU 90I en el primer cas, del cicle del beneit en el segon i del tipus ATU 879 en el tercer. El treball de Grimalt inclou unes interessants reflexions al voltant del suposat antifeminisme d'Alcover (p. 2I6-2I8), reflexions generades a partir del debat sorgit en la mateixa trobada ERGON / GRENO a Galícia. Això evidencia els avantatges d'aquestes trobades i és una mostra més de l'enriquiment de les publicacions posteriors.

IO. Proposat inicialment pel mateix autor a GonZÁlEz SANZ, Carlos (I996): Catálogo tipológico de cuentos folklóricos aragoneses. Saragossa: Instituto Aragonés de Antropología, i ampliat en estudis posteriors. 
Caterina Valriu estudia les llegendes del corpus català al voltant de la figura femenina en el moment mític de la creació del món. A «¿Por qué las mujeres tienen menos cerebro que los hombres? Las leyendas catalanas sobre la figura femenina en la Creación del mundo» divideix el corpus estudiat, format per vint-i-sis relats, en quatre grups diferents: sobre la creació del món, sobre la creació de la dona (que inclou la visió negativa que associa el sexe amb el diable, així com la imatge de la «mitja taronja»), sobre les característiques específiques de la dona (amb narracions de caràcter etiològic i amb la presència de Nostre Senyor i sant Pere) i, finalment, sobre la descendència d'Eva (ATU 758). L'autora parteix de versions catalanes identificades a l'índex ATU, així com altres que no tenen correspondència a l'índex internacional, però que han estat catalogades al projecte «RondCat: rondalles catalanes». ${ }^{\text {II }}$ És el cas, per exemple, del tipus C-oo8, que apareix en el títol del mateix article.

L'estudi que tanca aquesta segona secció està escrit a quatre mans per Josiane Bru i Carme Oriol i porta per títol «Pour une typologie des figures féminines des récits oraux traditionnels». Les autores parteixen de l'índex ATU i dels projectes de catalogació de les rondalles catalanes i franceses i de les llegendes portugueses per examinar la diferent tipologia dels personatges femenins i com la seva presència a les rondalles pot ser útil per a una classificació que abraci també les llegendes. En aquest sentit, exposen diferents consideracions que cal tenir en compte en un estudi d'aquest tipus, com són aquells relats que es poden trobar indistintament en forma de rondalla o de llegenda (la majoria, rondalles religioses), les etapes de la vida de la protagonista i el seu punt de vista femení. L'estudi inclou un annex amb la llista completa dels tipus que han tingut en compte, convenientment classificats (p. 255-259). Es tracta d'una completa i il-lustrativa mostra que conjuga l'estudi de la figura femenina i les relacions entre diferents gèneres.

La tercera secció, dedicada a la imatge de la dona en les llegendes medievals portugueses, està formada per l'estudi «Lendas da Fundaçao de Portugal: as mulheres nas relações de amor e de guerra» d'Emília Lemos. L'autora té en compte trenta-vuit relats que comparteixen el context exposat en el títol i que desenvolupen diferents temes relacionats, com són els grans amors entre moros i cristians, la doble figura de la dona (luxuriosa i casta), la dona com a botí de la conquesta, la muller legitimada per l'acte amorós, la fidelitat amorosa, els amors entre cristians o el poder de la dona donzella.

Finalment, María Inés Palleiro tanca el volum amb la darrera secció, dedicada a dues llegendes urbanes argentines, i formada per l'article «Mujeres fantasmas en el barrio porteño de La Boca: Felicitas Guerrero y la joven Clementina». Palleiro parteix d'un corpus heterogeni format per versions orals, versions enregistrades en vídeo, versions cinematogràfiques i versions presents a Internet. Aquestes llegendes de dones fantasmes tenen relació amb el motiu E.322.33.I de Thompson i, fins i tot, amb els follets de la tradició catalana (p. 298). L'autora presenta una possible derivació del tema estudiat, amb l'ús de la llegenda com a guió multimèdia d'un museu i la versió cinematogràfica. En definitiva, diferents cares per a una mateixa història que ha sobreviscut al pas del temps.

II. Per als detalls, vegeu la base de dades RondCat: cercador de la rondalla catalana <http:// www.sre.urv.cat/rondcat> [data de consulta: setembre DE 2013]. 
Els estudis inclosos a Imaxes de muller són de lectura obligada si es vol investigar la figura de la dona en la literatura oral, però també si es vol aprofundir en la difícil tasca d'estudiar les relacions entre diferents gèneres de la literatura oral, com poden ser la rondalla i la llegenda. La diversitat cultural dels corpus estudiats en cada article, reflectida també en el mateix plurilingüisme del llibre (que inclou articles en gallec, espanyol, portuguès, francès i alemany), enriqueix el conjunt i és una prova més de la importància d'aquest tipus d'estudis i de les relacions que cal establir (i fomentar) entre investigadors de diferents centres que comparteixen interessos i inquietuds. La seva interacció (en format de trobada o de publicació científiques) dóna com a resultat aportacions altament enriquidores com les que trobem en aquest volum. 